\title{
Chemisorption of methanol on different platinum electrodes (smooth and rough polycrystalline, monocrystalline, and preferentially oriented), as studied by EMIRS
}

\author{
B. Beden, F. Hahn, C. Lamy and J.M. Léger \\ Laboratoire de Chimie I, UA au CNRS No. 350, Université de Poitiers, 40 Avenue du Recteur Pineau, \\ 86022 Poitiers (France)
}

\author{
N.R. de Tacconi, R.O. Lezna and A.J. Arvia \\ Instituto de Investigaciones Fisicoquímicas Teóricas y Aplicadas (INIFTA), Facultad de Ciencias Exactas, \\ Universidad Nacional de La Plata, Sucursal 4, Casilla de Correo I6, 1900 La Plata (Argentina)
}

(Received 25 November 1988)

\begin{abstract}
EMIR spectra of methanol electroadsorbates on smooth and rough polycrystalline, monocrystalline and preferentially oriented platinum electrodes are reported. The (100)-type preferred oriented platinum behaves approximately as Pt (100) single crystals. On electrodispersed platinum electrodes the poisoning phenomena due to $\mathrm{CO}$ adsorbates appear to be reduced as compared to smooth platinum electrodes. EMIRS results correlate well with the electrochemical behaviour of the different platinum electrodes for methanol electrooxidation.
\end{abstract}

\section{INTRODUCTION}

In the course of the electrocatalytic oxidation of $\mathrm{CO}$ and other simple organic fuels on platinum, the formation of $\mathrm{CO}$-adsorbed species leads to catalytic poisoning of the reaction sites. The nature of these species has been well established through in situ reflectance IR techniques [1-3], but some important questions still remain to be answered, such as the role played by the crystallographic structure of the platinum substrate and the specific influence of the surface roughness on the nature and distribution of adsorbates. Special attention can be given to this problem by encouraging a comparative investigation of the behaviour of the poisons resulting from the electrocatalytic oxidation of methanol on single crystal, preferred oriented and electrodispersed platinum in acid solutions, by using EMIRS and conventional voltammetry. 


\section{EXPERIMENTAL}

The following four types of platinum electrodes were employed: (i) Smooth polycrystalline platinum, mirror polished with the finest grade alumina powder $(0.05$ $\mu \mathrm{m})$; (ii) thermally treated Pt (100) single crystals, prepared according to the technique described by Clavilier et al. [4]; (iii) (100)-type preferred oriented platinum made through the application of fast periodic perturbing potentials as indicated elsewhere [5]; (iv) electrodispersed platinum electrodes with a roughness factor of about 20 , which were obtained by electroreducing a hydrous platinum oxide layer accumulated by means of a periodic perturbing potential treatment under the conditions described in the literature [6]. All these electrodes were employed in 0.5 $M \mathrm{HClO}_{4}+x M$ methanol, with $0.01 \leqslant x \leqslant 1$, at $25^{\circ} \mathrm{C}$. Conventional voltammograms were recorded for the base electrolyte and for the methanol containing solutions at $0.05 \mathrm{~V} / \mathrm{s}$ between $0 \mathrm{~V}$ and an upper switching potential ranging from 0.8 to $1.5 \mathrm{~V}$. Potentials are referred to the RHE scale. Several series of EMIR spectra were recorded at constant step amplitude and different potential steps. Spectra were also taken at similar steps but different spectral accumulations (e.g. 1, 5 , and 10 scans).

\section{RESULTS AND DISCUSSION}

The results found for methanol containing solutions in contact with conventional smooth platinum electrodes (Fig. 1) are presented for the sake of comparison. The corrcsponding voltammogram (Fig. 1a) exhibits a wide and complex electrooxidation peak which initiates at ca. $0.35 \mathrm{~V}$ and is centered at ca. $0.75 \mathrm{~V}$. The reverse potential scan also shows an electrooxidation peak following methanol readsorption. 'This voltammogram shows a decrease in the $\mathrm{H}$-adatom electroadsorption/electrodesorption peak of about $25 \%$ as compared to that of the base electrolyte, due to the presence of methanol. When the mean value of the modulating potential, $\bar{E}$, is 0.3 $\mathrm{V}$, the corresponding EMIR spectrum (Fig. 1b) shows clearly a maximum contribution of the bipolar peak at $2040-2060 \mathrm{~cm}^{-1}$, currently assigned to linearly adsorbed $\mathrm{CO}$ on the basis of earlier measurements [7]. This adsorbate already exists at $\bar{E}=0.2 \mathrm{~V}$, but it tends to disappear for $\bar{E}=0.4 \mathrm{~V}$, i.e. as the positive potential limit is just in the range of $\mathrm{CO}$ electrooxidation $[8,9]$. The spectra also show a band with negative sign at ca. $2350 \mathrm{~cm}^{-1}$, which can be attributed to $\mathrm{CO}_{2}$, as expected for an adsorbate which is present at the upper limit of the modulating potential. The spectra also present a complex band at ca. $1700 \mathrm{~cm}^{-1}$ (Fig. 1c) which coincides with the absorption spectral range for aldehydes and organic acid groups [10]. In addition, a band at $1850 \mathrm{~cm}^{-1}$, attributed to bridge-bonded $\mathrm{CO}$ adsorbates, can be noted. For the conditions of Fig. 1c, it becomes clear that, as the number of spectral scans goes from 1 to 10 , the intensity of the linear $\mathrm{CO}$ band increases, the intensities of the bands at $1700 \mathrm{~cm}^{-1}$ and $1850 \mathrm{~cm}^{-1}$ decrease, and that of the adsorbed $\mathrm{CO}_{2}$ band reaches a limiting valuc. 

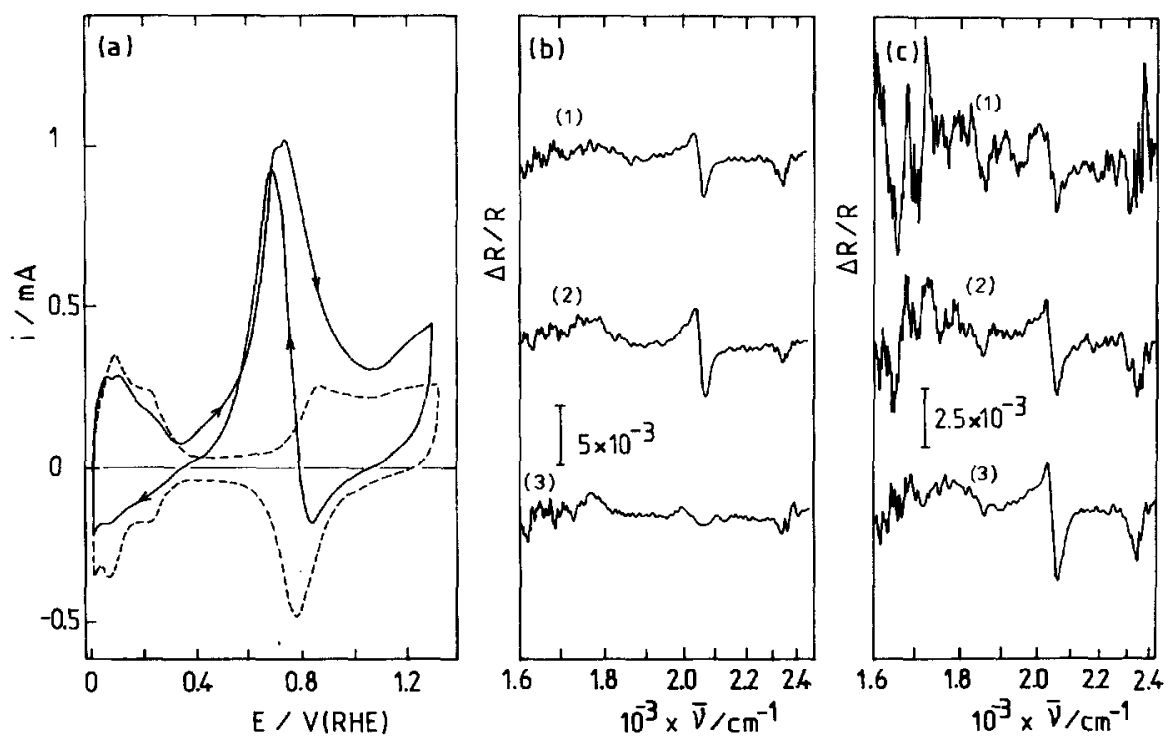

Fig. 1. (a) Voltammograms of a smooth platinum electrode in $0.5 \mathrm{M} \mathrm{HClO}_{4}(--\infty)$ and $0.5 \mathrm{M}$ $\mathrm{HClO}_{4}+10^{-2} M \mathrm{CH}_{3} \mathrm{OH}$ (—) at $25^{\circ} \mathrm{C}, v=50 \mathrm{mV} \mathrm{s}{ }^{-1} . \rho=2.1$. (b, c) EMIR spectra of the adsorbed species resulting from the chemisorption of $10^{-2} M \mathrm{CH}_{3} \mathrm{OH}$ in $0.5 \mathrm{M} \mathrm{HClO}$ at a smooth platinum electrode. $\Delta E=400 \mathrm{mV}, f=13.5 \mathrm{~Hz}$. (b): (1) $\bar{E}=200 \mathrm{mV} / \mathrm{RHE}, 10 \mathrm{scans}$; (2) $\bar{E}=300$ $\mathrm{mV} /$ RHE, 10 scans; (3) $\bar{E}=400 \mathrm{mV} /$ RHE, 10 scans. (c): (1) 1 scan, $\bar{E}=200 \mathrm{mV} /$ RHE; (2) 5 scans, $\bar{E}=200 \mathrm{mV} /$ RHE; (3) 10 scans, $\bar{E}=200 \mathrm{mV} /$ RHE.

The behaviour of electrodispersed platinum electrodes deserves more extended comment. In this case the voltammetric electrooxidation of methanol at $0.05 \mathrm{~V} / \mathrm{s}$ (Fig. 2a) commences at $0.5 \mathrm{~V}$, and it involves two broad peaks which extend to 1.35 $\mathrm{V}$. The reverse potential scan shows a small O-electrodesorption current together with a rather small methanol readsorption electrooxidation peak at ca. $0.8 \mathrm{~V}$. Likewise, in the presence of $0.1 M$ methanol, the $\mathrm{H}$-adatom voltammetric charge becomes diminished considerably, and the shape of the voltammogram in the $\mathrm{H}$-adatom potential range is therefore drastically modified as compared to that obtained for the base solution. The EMIR spectra obtained for the adsorption of methanol on electrodispersed platinum are the first ones which are reported for a rough metal surface, the morphology of which has been determined through STM [11]. Despite the high roughness factor of this type of electrode surface (about 20), reliable spectral signals can be obtained. The noise level is obviously higher than that recorded for the smooth surface, but this does not preclude obtaining reasonably good and reproducible EMIR spectra. The EMIR spectra for $1 M$ methanol, obtained with constant potential modulation window, frequency and number of spectral scans but with different values of $\bar{E}$ (Fig. 2b), show a maximum contribution of the bipolar absorption bands at $1850 \mathrm{~cm}^{-1}$ and $2050 \mathrm{~cm}^{-1}$ due to $\mathrm{CO}$ adsorbates for $\vec{E}=0.4 \mathrm{~V}$, and a contribution of the adsorbed $\mathrm{CO}_{2}$ band at ca. 2350 

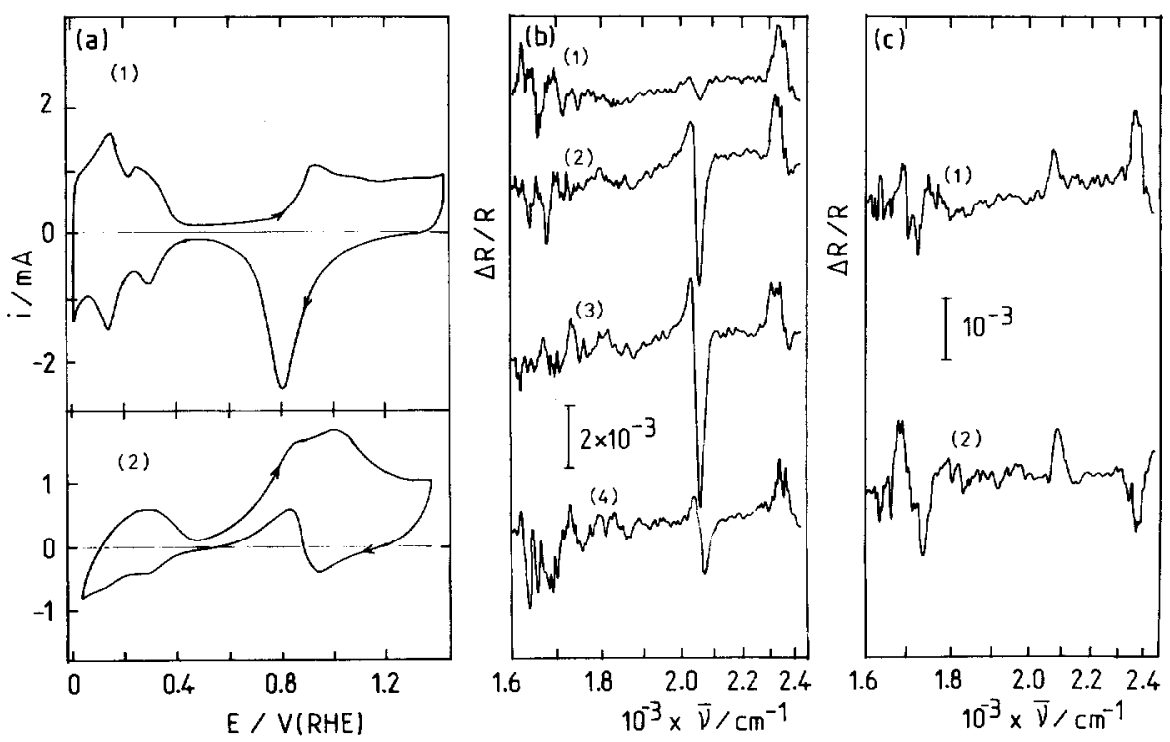

Fig. 2. (a) Voltammograms of a rough platinum electrode in $0.5 M \mathrm{HClO}_{4}$ (1) and $0.5 M \mathrm{HClO}_{4}+1 \mathrm{M}$ $\mathrm{CH}_{3} \mathrm{OH}(2)$ at $25^{\circ} \mathrm{C}, v=50 \mathrm{mV} \mathrm{s}^{-1} . \rho=20$. (b, c) EMIR spectra of the adsorbed species resulting from the chemisorption of $\mathrm{CH}_{3} \mathrm{OH}$ in $0.5 \mathrm{M} \mathrm{HClO}_{4}$ at a rough platinum electrode. $\Delta E=400 \mathrm{mV}, f=13.5$ Hz. (b): (1) $\bar{E}=200 \mathrm{mV} / \mathrm{RHE}, 1 M \mathrm{CH}_{3} \mathrm{OH}, 10$ scans; (2) $\bar{E}=300 \mathrm{mV} / \mathrm{RHE}, 1 M \mathrm{CH}_{3} \mathrm{OH}, 10$ scans;

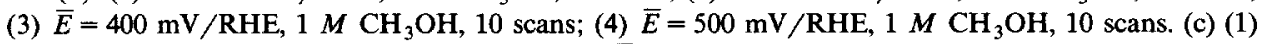
$\bar{E}=200 \mathrm{mV} / \mathrm{RHE}, 0.1 M \mathrm{CH}_{3} \mathrm{OH}, 15$ scans; (2) $\bar{E}=400 \mathrm{mV} / \mathrm{RHE}, 0.1 M \mathrm{CH}_{3} \mathrm{OH}, 15$ scans.

$\mathrm{cm}^{-1}$, for $\bar{E}$ ranging from 0.2 to $0.5 \mathrm{~V}$. The intensity of this band is relatively lower when the optical signal of adsorbed $\mathrm{CO}$ increases. This can be understood immediately in terms of reduced $\mathrm{CO}_{2}$ formation at the electrode surface $[12,13]$. The quasi-bipolar nature of the band (especially at $\bar{E}=0.4 \mathrm{~V}$ ) indicates that adsorbed $\mathrm{CO}_{2}$ is present at both the lower and the upper limits of the modulating potential. Conversely, in the case of smooth $\mathrm{Pt}$, the prevailance of the negative sign of the band is consistent with a weak adsorbate-substrate interaction which allows the adsorbate to be removed from the surface at the upper limit of the modulating potential. Therefore, a different situation is found for electrodispersed $\mathrm{Pt}$, where a stronger adsorbate-substrate interaction exists, due to the supercluster structure of this type of electrode [11], so that even at the upper limit of the modulating potential the adsorbate remains on the electrode surface.

On the other hand, the greatest contribution of the complex band centered at ca. $1700 \mathrm{~cm}^{-1}$, can presumably be assigned to the presence of organic radicals. The appearance of this hand is only possible when the surface is sufficiently cleaned of $\mathrm{CO}$ adsorbates. This result, which is valid for any methanol concentration, becomes clearer as the methanol concentration is decreased (Fig. 2c), in agreement with previous results [9]. 

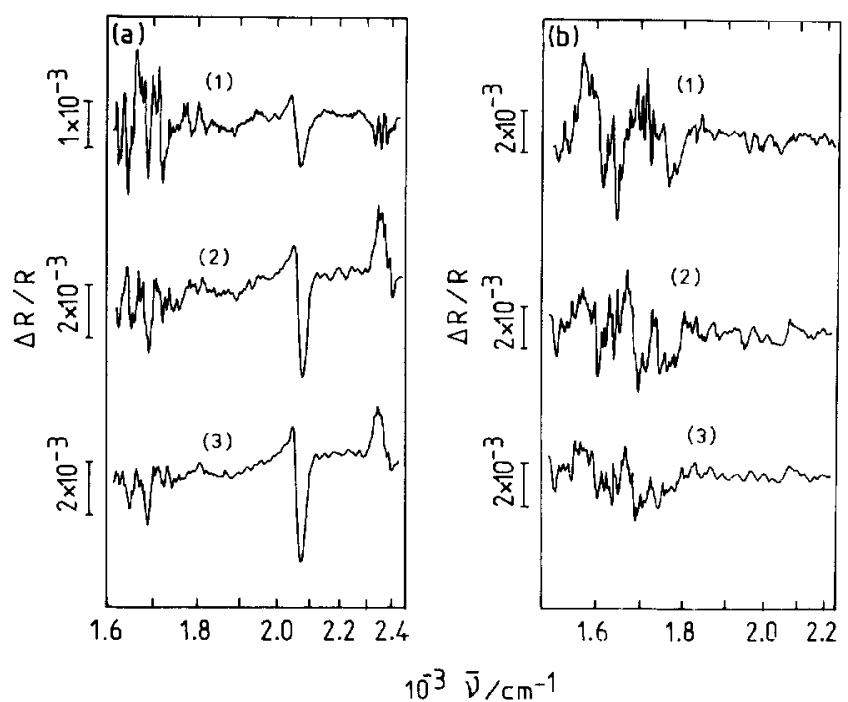

Fig. 3. (a, b) EMIR spectra of the adsorbed species resulting from the chemisorption of $\mathrm{CH}_{3} \mathrm{OH}$ in $0.5 \mathrm{M}$ $\mathrm{HClO}_{4}$ at a rough platinum electrode. $\Delta E=400 \mathrm{mV}, \bar{E}=200 \mathrm{mV} / \mathrm{RHE}, f=13.5 \mathrm{~Hz}$. (a) $1 \mathrm{M} \mathrm{CH} \mathrm{CH}_{3} \mathrm{OH}$, (1) 1, (2) 5, (3) 10 scans. (b) $0.1 \mathrm{M} \mathrm{CH}_{3} \mathrm{OH}$, (1) 1, (2) 5, (3) 10 scans.

The time dependence of the EMIR spectra (Fig. 3) for $1 M$ and $10^{-1} M$ methanol concentration was observed at $\bar{E}=0.2 \mathrm{~V}$ in order to obtain partial surface coverages by methanol species. For $1 M$ methanol the band centered at ca. 1700 $\mathrm{cm}^{-1}$ decreases during spectral accumulation, whereas the signal related to linear $\mathrm{CO}$ increases. The poisoning effect of linear $\mathrm{CO}$, accounting for this behaviour, is similar to that described for smooth platinum surfaces [9].

The band at ca. $1700 \mathrm{~cm}^{-1}$ on a rough $\mathrm{Pt}$ surface is seen better for $10^{-1} M$ methanol than for $1 \mathrm{M} \mathrm{MeOH}$. On electrodispersed platinum this band becomes much more intense than on smooth platinum and conversely, no $\mathrm{CO}_{\text {ads }}$ signals are detected. This fact is consistent with the decrease of the poisoning behaviour of the electrodispersed platinum.

The results obtained for (100)-type preferred oriented platinum electrodes, as far as voltammetry is concerned (Fig. 4a), show methanol electrooxidation peaks at potentials close to those already established for Pt (100) single crystals (Fig. 5a) [14]. For (100)-type preferred oriented platinum in $10^{-2} M$ methanol (Fig. 4a), the voltammogram shows only a slight decrease in the $\mathrm{H}$-adatom charge but the shape of the $i-E$ profile is modified considerably.

The EMIR spectra resulting for the (100)-type preferred oriented platinum (Figs. $4 \mathrm{~b}, \mathrm{c})$, under comparable conditions, exhibit features which are rather similar to those depicted in Figs. 5b, c for Pt (100). However, it should be noted that for the (100)-type preferred oriented platinum the contribution of bridge-bonded $\mathrm{CO}$ gives a band shifted towards lower wavelength numbers (by at least $100 \mathrm{~cm}^{-1}$ ). This would indicate a notable contribution of multibonded $\mathrm{CO}_{\mathrm{ads}}$ species at the lower 

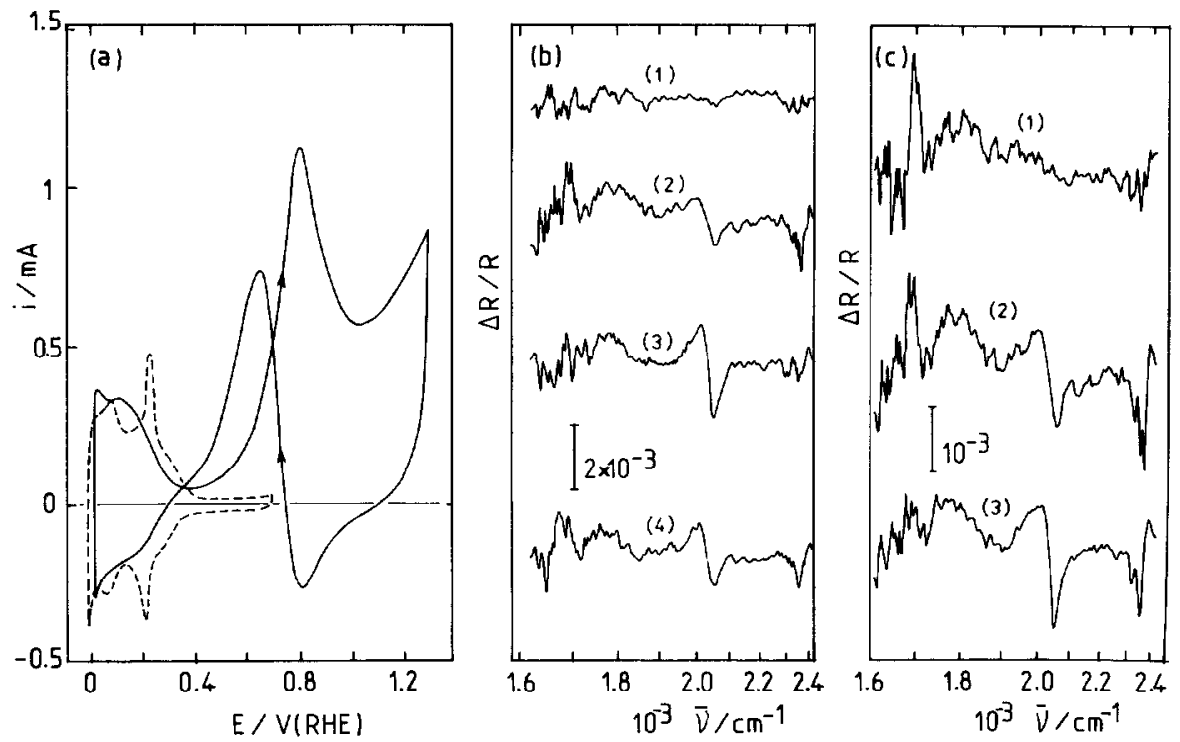

Fig. 4. (a) Voltammograms of a (100) preferentially oriented platinum electrode in $0.5 M \mathrm{HClO}_{4}$ $(--$,$) and 0.5 \mathrm{M} \mathrm{HClO}_{4}+10^{-2} \mathrm{M} \mathrm{CH} \mathrm{CH}_{3} \mathrm{OH}(-)$ at $25^{\circ} \mathrm{C}, v=50 \mathrm{mV} \mathrm{s}{ }^{-1}, \rho=1.7$. (b, c) EMIR spectra of the adsorbed species resulting from the chemisorption of $10^{-2} \mathrm{M} \mathrm{CH}_{3} \mathrm{OH}$ in $0.5 \mathrm{M}$ $\mathrm{HClO}_{4}$ at a (100) preferentially oriented platinum electrode. $\Delta E=400 \mathrm{mV}, f=13.5 \mathrm{~Hz}$. (b) 10 scans, $\bar{E}=$ (1) 100 , (2) 200, (3) 300, (4) $400 \mathrm{mV} /$ RHE. (c) $\bar{E}=200 \mathrm{mV} / \mathrm{RHE}$, (1) 1 , (2) 5, (3) 10 scans.
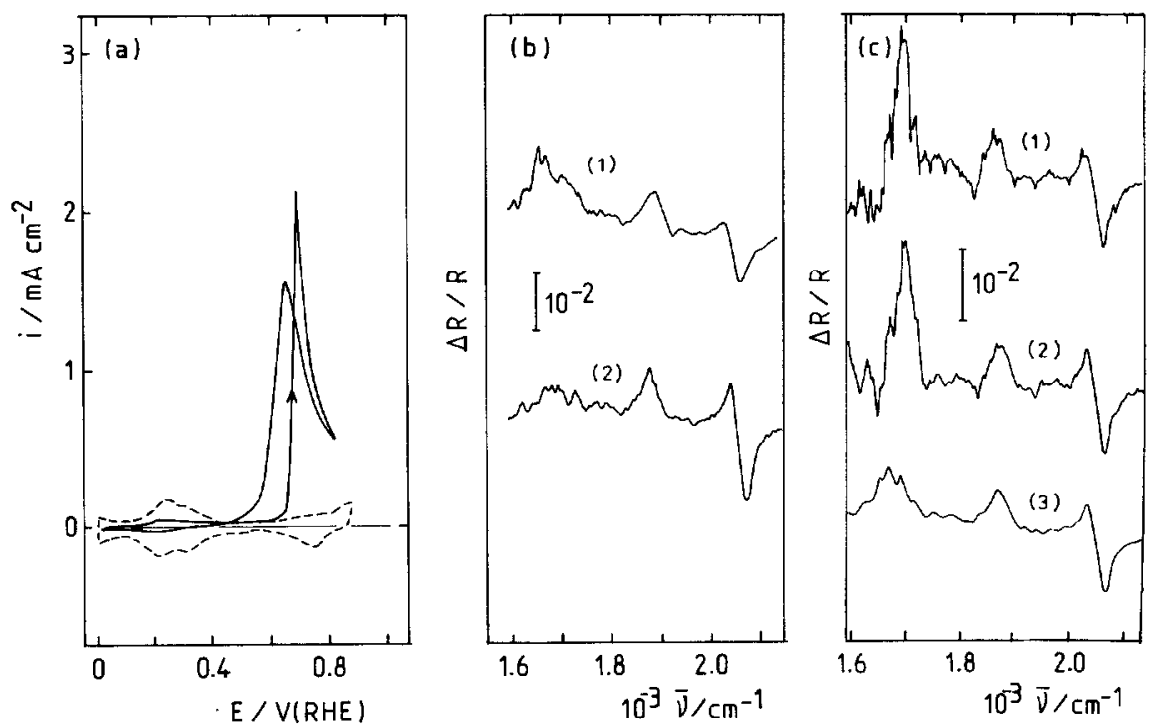

Fig. 5. (a) Voltammograms of a $\mathrm{Pt}(100)$ single-crystal electrode in $0.5 \mathrm{M} \mathrm{HClO}_{4}(--\infty)$ and $0.5 M$ $\mathrm{HClO}_{4}+10^{-1} M \mathrm{CH}_{3} \mathrm{OH}$ (— species resulting from the chemisorption of $10^{-1} M \mathrm{CH}_{3} \mathrm{OH}$ in $0.5 \mathrm{M} \mathrm{HClO}_{4}$ at a Pt (100) single-crystal electrode. $\Delta E=400 \mathrm{mV}, f=13.5 \mathrm{~Hz}$. (b) 10 scans, $\bar{E}=$ (1) 200 , (2) $350 \mathrm{mV} /$ RHE. (c) $\bar{E}=200$ $\mathrm{mV} / \mathrm{RHE}$, (1) 1, (2) 5, (3) 10 scans. 
potential limit. Conversely, as far as the band of the $\mathrm{CO}_{2}$ adsorbate is concerned (Figs. $4 \mathrm{~b}, \mathrm{c}$ ) the behaviour of the (100)-type preferred platinum becomes similar to that seen for the smooth platinum surface (Figs. 1b, c).

\section{CONCLUSIONS}

From the EMIRS results presented above, the following conclusions can be drawn for methanol chemisorption at different platinum electrodes:

(i) The surface structure of electrodispersed platinum electrodes [11] plays an important role in diminishing the poisoning phenomena due to $\mathrm{CO}$ adsorbates. This correlates well with previous electrochemical studies carried out on this type of electrode for the reduction of $\mathrm{CO}_{2}$ [15] and the electrooxidation of $\mathrm{CO}$ [16].

(ii) (100)-type preferred oriented platinum behaves approximately as $\mathrm{Pt}(100)$ single crystals, although the poisoning effects are also less intense for the oriented platinum electrodes, especially during the first scan.

(iii) EMIRS shows that for electrodispersed platinum, adsorbed $\mathrm{CO}_{2}$ species are already present at low potentials, in agreement with DMS results [17].

\section{ACKNOWLEDGEMENTS}

The authors are indebted to the French "Ministère des Affaires Etrangères" and the Argentinian "Ministerio de Educación" through a Scientific Cooperation Agreement between France and Argentina.

\section{REFERENCES}

1 A. Bewick and B.S. Pons in R.J.H. Clark and R.E. Hester (Eds.), Advances in Infrared and Raman Spectroscopy, Vol. 12, Wiley-Heyden, London, 1985, Ch. 1.

2 A. Bewick, K. Kunimatsu, B.S. Pons and J.W. Russell, J. Electroanal. Chem., 160 (1984) 47.

3 B. Beden and C. Lamy in R.J. Gale (Ed.), Spectroelectrochemistry, Theory and Practice, Plenum Press, New York, 1988, Ch. 5.

4 J. Clavilier, G. Guinet, R. Faure and R. Durand, J. Electroanal. Chem., 107 (1980) 205.

5 R.M. Cerviño, W.E. Triaca and A.J. Arvia, J. Electroanal. Chem., 182 (1985) 51; W.E. Triaca, T. Kessler, J.C. Canullo and A.J. Arvia, J. Electrochem. Soc., 134 (1987) 1165.

6 A.C. Chialvo, W.E. Triaca and A.J. Arvia, J. Electroanal. Chem., 146 (1983) 93.

7 B. Beden, A. Bewick, K. Kunimatsu and C. Lamy, J. Electroanal. Chem., 121 (1981) 343.

8 S.A. Bilmes and A.J. Arvia, J. Electroanal. Chem., 198 (1986) 137; E.P.M. Leiva, E. Santos, M.C. Giordano, R.M. Cerviño and A.J. Arvia, J. Electrochem. Soc., 133 (1986) 1660.

9 B. Beden, F. Hahn, S. Juanto, C. Lamy and J.M. Leger, J. Electroanal. Chem., 225 (1987) 215.

$10 \mathrm{~K}$. Nakamoto, Infrared Spectra of Inorganic and Coordination Compounds, Wiley-Interscience, New York, 1970.

11 L. Vásquez, J. Gómez, A.M. Baró, N. García, M.L. Marcos, J. González-Velasco, J.M. Vara, A.J. Arvia, J. Presa, A. García and M. Aguilar, J. Am. Chem. Soc., 109 (1987) 1730; J. Gómez, L. Vásquez, A.M. Baró, C. Alonso, E. González, J. González-Velasco and A.J. Arvia, J. Electroanal. Chem., 240 (1988) 77.

12 J. Giner, Electrochim. Acta, 8 (1963) 857; 9 (1964) 63. 
13 B. Beden, A. Bewick, M. Razaq and J. Weber, J. Electroanal. Chem., 139 (1982) 203.

14 S. Juanto, B. Beden, F. Hahn, J.M. Léger and C. Lamy, J. Electroanal. Chem., 237 (1987) 119.

15 M.L. Marcos, J.M. Vara, J. González-Velasco and A.J. Arvia, J. Electroanal. Chem., 224 (1987) 189.

16 A.M. Castro Luna, M.C. Giordano and A.J. Arvia, J. Electroanal. Chem., 259 (1989) 173.

17 J. Willsau, O. Wolter and J. Heitbaum, J. Electroanal. Chem., 185 (1985) 163. 